\title{
SUPERCONDUCTING MAGNETS AND CRYOGENICS
}

\author{
by
}

John R. Purceil

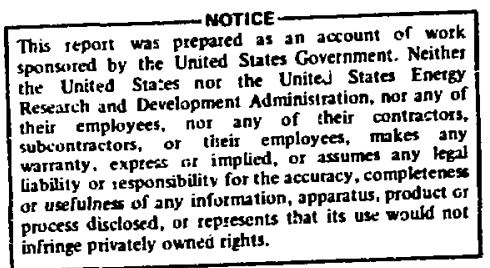

\section{ARGONNE NATIONAL LABORATORY, ARGONNE, ILLINOIS}




\title{
SUPERCONDUCTING MAGNETS AND CRYOGENICS*
}

\author{
John R. Purcell \\ Argonne National Laboratory \\ Argonne, Illinois 60439
}

\section{Summary}

Several significant superconducting beam line magnet systems are being constructed in the U.S. These will demcnstrate the practicability of superconductors in beam lines. It is now time to consider some of the more subtle engineering problems associated with these magnets in order to assure a "next generation" of highly usable magnets. This paper presents some engineering approachs to better maznets for the future.

At present in the U.S. work on several significant superconducting beam line magnet systems is in progress. At Brookhaven National Laboratory they are constructing a secondary beam line ${ }^{1}$ to give a 200 bend at $30 \mathrm{GeV} / \mathrm{c}$ to go into operation durirg the fall of 1975. At Argonne we are going to use the SSR (Superconducting Stretcher Ring) prototype magnets 2 to give a $33^{\circ}$ bend at $12 \mathrm{GeV} / \mathrm{c}$ in the beam to the Argonne Effective Mass Spectrometer. This line will be in operation in late 1975. ISCAR (Experimental Superconducting Accelerator Ring) ${ }^{3}$ is proceeding and construction should start soon. Fermi National Accelerator Laboratory not only is planning the Energy Doubler, 4 but numerous external beam line $s^{5}$ as well. It seems that at long last the time has come to use superconductors "en masse" to control high energy particle beams.

A puzzling thing is why beam line magnets took so long in "coming of age" (approximately ten years) when other uperconducting magnets have been in use for many years. Part of the answer is, of course, that beam line magnets with precision field requirements and small size are harder to build than large experimental area vnagnets and funds for this type of development heve been short. I don't believe that this is the complete answer and that understanding the errors of the past may help the future in utilization of superconductivity.

Designers of conventional room-temperature magnets know that the important parameters for the magnets are initial cost, power consumption, a field distribution which will do the job, and reliability. A corresponding measure of a superconducting magnet is initial cost, heat leik, a field distribution which will do the job, and reliability. It is worth noting that a figure of merit for superconducting magnets is not current density or percent of short sample. They are important only in their effect on the main parameters, principally initial cost and reliability. Part of the problems in magnet development can be
It will have a heat leak to the liquid no liquid nitrogen shield; will withst: transporting by truck; and is good fo; static vacuum system. This is in $\mathrm{sh}^{7}$ most magnet cryostats that are more. factors of 5 to 10 , have higher heat 1 of magnitude, and are fragile. The must support more weight than a liqu and may need to be adjustable for ali but it still seems we could do a lot b? stats by more fully utilizing dewar to haps as magnets become more predic will be put into the cryogenics of the the present huge gap between comme laboratory inagnet cryostats.

In the cryogenic design of magn distinct types. One type, such as acce generates heat at $4^{\circ} \mathrm{K}$ due to pulsing. is steady state and generates no appr $4^{\circ} \mathrm{K}$. Beam line magnets (with neglig ing), bubble chamber magnets, and $e^{t}$ magnets are examples of the latter ty genic design of the se two types is con For magnets whose main source of he from ambient temperatures, the most od of keeping them cool is by cold boi the liquid helium. This is such a wel fact for current leads that it is comm cool them with cold boiloff gas, but w ignored is that the same principles ay coming in from the outside; i. e., it cepted with cold boiloff gas.

In practice, it is sometimes $m$ cool the radiation shield and support uid nitrogen. This frees more of the used for the leads. A good lead intro $1,000 \mathrm{~A}$ into the liquid when it is gen intercept gas. If intercept gas is ave other source within the cryostat and through the leads, the additional heat approaches zero. A 1-W dewar with is not a $2-W$ system, but is less than combination, as long as all the boilo, through the leads.

These factors lead to a design steady state magnets that will optimi of the system. First the cryostat is out current leads to give as low a he economically feasible, using liquid nit ing. For example, if this turns out the magnet should operate at 1,000 leads. If the magnet is designed to 
CRCONDUCTING MAGNETS AND CRYOGENICS*

\author{
John R. Purcell \\ Argonne National Laboratory \\ Argonne, Illinois 60439
}

\title{
ANL-HEP \$5:07
Conf- $750335-240$
}

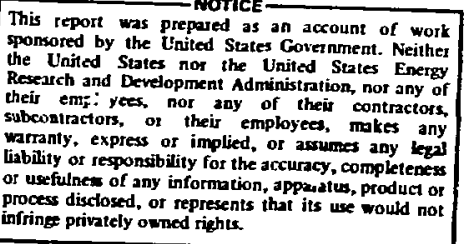

aducting beam line icted in the U.S. cability of super. ow time to consider ing problems assor to assure a "next lets. This paper chs to better mag-

on several signifiagnet systems is in 21 Laboratory they m line ${ }^{1}$ to give a peration during the zoing to use the (ing) prototype $\mathrm{GeV} / \mathrm{c}$ in the beam ctrometer. This 75. ESCAR (Exlerator Ring) ${ }^{3}$ is ld start soon. Fermi pot only is planning is external beam ong last the time "en masse" to s.

m line magnets took cimately ten year 8 ) ts have been in use yer is, of course, tsion field requireto build than large inds for this type I don't believe that hat understanding te future in utiliza-

oom-temperature barameters for the onsumption, a field and reliability. A conducting magnet fistribution which is worth noting nducting magnets of short sample. ffect on the main tot and reliability.
It will have a heat leak to the liquid of $0.146 \mathrm{~W}$ with no liquid nitrogen shield; will withstand the shock of transporting by truck; and is good for years with a static vacuum system. This is in sharp contrast to most magnet cryostats that are more expensive by factors of 5 to 10, have higher heat leaks by crders of magnitude, and are fragile. The magnet cxyostat must support more weight than a liquid helium dewar and may need to be adjustable for alignment purposes, but it still seems we could do a lot better with cryostats by more fully utilizing dewar technology. Perhaps as magnets become more predictable more effort will be put into the cryogenics of the system and close the present huge gap between commercial dewars and laboratory magnet cryostats.

In the cryogenic design of magnets there are two distinct types. One type, such as accelerator magnets, generates heat at $4^{\circ} \mathrm{K}$ due to pulsing. The other type is steady state and generates no appreciable heat at $40 \mathrm{~K}$. Beam line magnets (with negligible beam heating), bubble chamber magnets, and experimental area magnets are examples of the latter type. The cryogenic design of the se two types is completely different. For magnets whose main source of heat is heat leak from ambient temperatures, the most efficient method of keeping them cool is by c sldboiloff gas from the liquid helium. This is such a vell-understood fact for current leads that it is common practice to cool them with cold boilcff gas, but what is gencialsy ignored is that the same principles apply for all heat coming in from the outside; i. e., it should be intercepted with cold boiloff gas.

In practice, it is sometimes more convenient to cool.the radiation shield and support system with liquid nitrogen. This frees more of the boiloff gas to be used for the leads. A good lead introduces $1 \mathrm{~W}$ per $1,000 \mathrm{~A}$ into the liquid when it is generating its own intercept gas. If intercept gas is available from another source within the cryostat and this gas is passed through the leads, the additional heat from the leads approaches zero. A 1-W dewar with a 1,000-A lead is not a $2-W$ system, but is less than $1.2 \mathrm{~W}$ for the combination, as long as all the boiloff gas is taken through the leads.

These factors lead to a design procedure for steady state magnets that will optimize the heat leak of the system. First the cryostat is clesigned without current leads to give as low a heat leak as is economically feasible, using liquidnitrogen for shielding. For example, if this turns out to be $2 \mathrm{w}$, then the magnet should operate at $1,000 \mathrm{~A}$ with optimum 
presents some engineering approachs to better magnets for the future.

At present in the U.S. work on several significant superconducting beam line magnet systems is in progress. At Brookhaven National Laboratory they are constructing a secondary beam line ${ }^{1}$ to give a 200 bend at $30 \mathrm{GeV} / \mathrm{c}$ to go into operation during the fall of 1975. At Argonne we are going to use the SSR (Superconducting Stretcher Ring) prototype magnets 2 to give a $33^{\circ}$ bend at $12 \mathrm{GeV} / \mathrm{c}$ in the beam to the Argonne Effective Mass Spectrometer. This line will be in operation in late 1975. ESCAR (Experimental Superconducting Accelerator Ring) ${ }^{3}$ is proceeding and construction should start soon. Fermi National Accelerator Laboratory not only is planning the Energy Doubler, 4 but numerous external beam lines 5 as well. It seems that at long last the time has come to use superconductors "en masse" to control high energy particle beams.

A puszling thing is why beam line magnets took so long in "coming of age" (approximately ten years) when other superconducting magnets have been in use for many years. Part of the answer is, of course, that beam line magnets with precision field requirements and small size are harder to build than large experimental area onagnets and funds for this type of development have been short. I don't believe that this is the complete answer and that understanding the errors of the past may help the future in utilization of superconductivity.

Designers of conventional z som-temperature magnets know that the important parameters for the magnets are initial cost, power consumption, a field distribution which will do the job, and reliability. A corresponding measure of a superconducting magnet is initial cost, heat leak, a field distribution which will do the job, and reliability. It is worth noting that a figure of merit for superconducting rnagnets is not current density or percent of short sample. They are important only in their effect on the main parameters, principally initial cost and reliability. Part of the problems in magnet development can be directly traced to the feeling that current density in itself is important and should be as high as possible, in disregard of the fact that stability problems increase in proportion to the current density squared.

An example of not utilizing existing technology is in magnet cryostats. Commercially, a 500-l liquid helium dewar can be purchased for about $\$ 6,000$.

*Work supported by the U.S. Energy Research and Development Administration. but it still seems we could do a lut bette stats by more fully utilizing dewar techn haps as magnets become more predictab will be put into the cryogenics of the sy: the present huge gap between commerci laboratory magnet cryostats.

In the cryogenic design of magnets distinct types. One type, such as acceler: generates heat at $4^{\circ} \mathrm{K}$ due to pulsing. T is steady state and generates no apprecia $40 \mathrm{~K}$. Beam line magnets (with negligible ing), bubble chamber magnets, and expej magnets are examples of the latter type. genic design of the se two types is comple For magnets whose main source of heat 1 from ambient temperatures, the most eff od of keeping them cool is by coldboiloff the liquid helium. This is such a well-us fact for current leads that it is common if cool them with cold boiloff gas, but what ignored is that the same principles apply coming in from the outside; $1 . e_{.}$, it shou cepted with cold boiloff gas.

In practice, it is sometimes more cool the radiation shield and support sys uid nitrogen. This frees more of the boi used for the leads. A good lead introduc $1,000 \mathrm{~A}$ into the liquid when it is generaf intercept gas. If intercept gas is availat other source within the cryostat and this through the leads, the additional heat fro approaches zero. A $1-W$ dewar with a 1 is not a $2-W$ system, but is less than 1. combination, as long as all the boiloff ga through the leads.

These factors lead to a design pro steady state magnets that will optimize $t$ of the system. First the cryostat is des out current leads to give as low a heat le economically feasible, using liquidnitrog ing. For example, if this turns out to $b$ the magnet should operate at $1,000 \mathrm{~A}$ wi leads. If the magnet is designed to operi current, then the heat leak will still be ing will be gained by the lower current. is designed for a higher current, then th um boiloff rate will increase accordingly

A system that c perates by transfer helium in $\mathrm{kitches}$ to the magnet and retui gas back to the liquefier has other impos tages. The system is not dependent on frigerator running continuously. A rese can be kept to serve during the time the

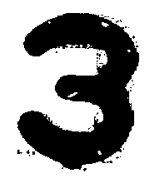


Sral signifi$y$ stems is in ratory they to give a during the use the totype in the beam ter. This CAR (Ex(Ring) ${ }^{3}$ is soon. Fermi is planring nal beam the time sse" to

nagnets took y ten yearol

been in use tof course, ld requirethan large this type believe that serstanding fe in uililiza -

mperature ters for the tion, a field liability. A ting magnet ition which rth noting ig magnets t sample. in the main reliability. nent can be $t$ density in as possible, blens inty squa red.

technology a 500-\& liqbout $\$ 6,000$. earch and atats by more fully utilizing dewar technology. Perhaps as magnets become more predictable more effort will be put into the cryogenics of the system and close tha present huge gap between commercial dewars and laboratury magnet cryostats.

In the cryogenic design of magnets there are two distinct types. One type, such as accelerator magnets, generates heat at $4^{\circ} \mathrm{K}$ due to pulsing. The other type is steady state and generates no appreciable heat at 4\% $\mathrm{K}$. Beam line magnets (with negligible beam heating), bubble chamber magnets, and experimenlal area magnets are examples of the latter type. The cryogenic design of the se two types is completely different. For magnets whose main source of heat is heat leak from ambient temperatures, the most efficient method of keeping them cool is by coldboiloff gas fronl the liquid helium. This is such a vell-under stood fact for current leads that it is common practice to cool them with cold boiloff gas, but what is gcresain; ignored is that the same principlesapply for all heat coming in from the outside; i. e., it should be intercepted with cold boiloff gas.

In practice, it is sometimes more convenient to cool the radiation shield and support system with liquid nitrogen. This frees more of the boiloff gas to be used for the leads. A good lead introduces $1 \mathrm{~W}$ per $1,000 \mathrm{~A}$ into the liquid when it is generating its own intercept gas. If intercept gas is available from another source within the cryostat and this gas is passed through the leads, the additional heat from the leads approaches zero. A $1-W$ dewar with a 1,000-A lead is not a $2-\mathrm{W}$ system, but is less than $1.2 \mathrm{~W}$ for the combination, as long as all the boiloff gas is taken through the leads.

These factors lead to a design procedure for steady state magnets that will optimize the heat leak of the system. First the cryostat is designed witinout current leads to give as low a heat leak as is economically feasible, using liquid nitrogen for shielding. For example, if this turns out to be $2 \mathrm{~W}$, then the magnet should operate at 1,000 A with optimum leads. If the magnet is designed to operate at a lower current, then the heat leak will still be $2 \mathrm{~W}$ and nothing will be gained by the lower current. If the magnet is designed for a higher current, then the liquid lielium boiloff rate will increase accordingly.

A system that operates by transferring the liquid helium in batches to the magnet and returns only warm gas back to the liquefier has other important advantages. The system is not dependent on a helium refrigerator running continuously. A reservoir of liquid can be kept to serve during the time the liquefier is

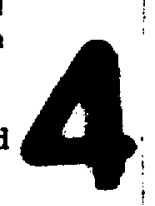

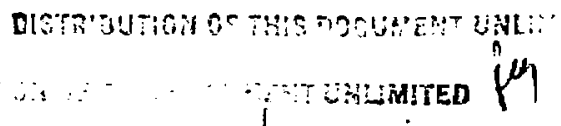


$\rightarrow \infty$

down for repails or maintenance. Onily one cold line is required to each magnet and this line is only used during refilling; taking perhaps one hour per day, making the heat leak of the transfer lines much less important.

A fact that leads designers to use a refrigerator rather that a liqucfier is that a typical $100 \mathrm{l} / \mathrm{h} \mathrm{ma-}$ chine can deliver $400 \mathrm{~W}$ at $4^{\circ} \mathrm{K}$ when in a refrigeration mode. When the $400 \mathrm{~W}$ is compared to the latent heat of 7C W for the $100 \ell / h$, it would seem wise to use the machine as a refrigerator. What is overlooked is that the sensible heat of gas amounts to $\approx 50 \mathrm{~W} / \mathrm{h}$ per liter in warming from $4^{\circ} \mathrm{K}$ to room temperature. This means that evaporating $100 \ell$ of liquid helium per hour can intercept close to $5,000 \mathrm{~W}$ of heat from the room temperature environment.

A well-designed "warm gas return system" is not only more efficient, but is easier to operate and has greater reliability because the system is not tied to continuous operation of refrigeration machinery. The SSR magnet system ${ }^{2}$ was designed with these parameters in mind with the result that the helium boiloff rate for a $10-\mathrm{ft}$ module containing three magnets is less than $1 / / \mathrm{h}$ and time between refills is greater than 24 hours.

For magnets that are pulsed or which have a heavy radiation load and thus have a heat load at $40 \mathrm{~K}$, a refrigerator should be used to remove the pulsing portion of the heat load. The heat leak portion of the heat load should be minimized by boiloff gas interception as with steady state magnets.

The high energy physics community has been the leader in the use of superconducting magnets with bubble chamber magnets such as the ANL 12-ft, the BNL 7-ft, the NAL 15-ft, and the CERN BEBC; var ious experimental area type magnets; and magnets for use with polarized proton targets. However, other needs are rapidly approaching. In the near future (approximately ten years) the magnetohydrodynamic (MHD) program will require magnets suitable for full scale power plants. These will be $60 \mathrm{kG}$ dipoles with a $3 \mathrm{~m} \times 3 \mathrm{~m}$ aperture, 15 to $20 \mathrm{~m}$ long. The next generation fusion device, called an experimental power reactor, is scheduled for completion in 1985 . Each D-shaped toroidal fie?d coil will be about $10 \mathrm{~m}$ tall and $7 \mathrm{~m}$ across. Twelve to twenty - four such coils mounted together to form a "doughnut" snape will comprise the complete toroidal field winding.
The peak field will be 75 to $80 \mathrm{kG}$ and th toroidal field will have a stored energy In addition to the toroidal field coils, the require superconducting ohmic heating c are solenoidal windings with a stored en eral hundred MJ. The coils must be pul $-80 \mathrm{kG}$ to $+80 \mathrm{kG}$ in a time of about $1 \mathrm{sec}$ attempt to meet the needs of the MHD pr fusion program with watercooled copper require a staggering amount of power an tainly make these energy sources much 1

Perhaps with these other users for ducting magnets appearing, the developm be shared, rather than borne by high ene: alone. The development of superconduct and $M H D$ will not be aimed at high energ magnets, but the "spin off"' benefits will profit us all. Oak Ridge National Labor multimillion dollar development program to be used in fusion machines. This pro lead to a better understanding of magnet: and provide design information useful for physics magnets.

\section{REFERENCES}

1. G. Morgan, et al., "Superconducting tem for the AGS High Energy Unsepar 1975 Particle Accelerator Conference (March 1975).

2. J. Purcell, et al., "Mngnets for the conducting Stretcher Ring," presented Applied Superconductivity Conference, iil. (Sept. 30-Oct. 2, 1974).

3. W. S. Gilbert, et al., "ESCAR Super Magnet System," 1975 Particle Accel ference, Session D (March 1975).

4. W. B. Fowler, et al., "The Fermilak Doubler, a Two-Year Progress Repor Particle Accelerator Conference, Ses (March 1975).

5. P. Gavin, et al., "Operation of Super Magnets in Fermilab Extracted Beam Particle Accelerator Conference, con paper (March 1975). 
ne cold line only used Ir per day, much less

refrigerator 100 l/h mafrigeration latent heat ie to use the oked is that /h per liter . This im per hour in the room

ystem" is perate and is not tied chinery. th these helium hree mag refills is

$h$ have a oad at $4^{\circ} \mathrm{K}$, e pulsing tion of the is inter-

has been gnnets with $12-\mathrm{ft}$, the EBC; varpagnets for er, other Ir future odynamic ble for kG dipoles . The perimental 3 in 1985. bout $10 \mathrm{~m}$ I such "' shape inding.
The peak field will be 75 to $80 \mathrm{kG}$ and the complete toroidal field will have a stored energy of $4,000 \mathrm{MJ}$. In addition to the toroidal field coils, the device will require superconducting ohmic heating coils, which are solenoidal windings with a stored energy of several hundred MJ. The coils must be pulsed from $-80 \mathrm{kG}$ to $+80 \mathrm{kG}$ in a time of about 1 second. To attempt to meet the needs of the MHD program or the fusion program with watercooled copper magnets would require a staggering amount of power and would certainly make these energy sources much less attractive.

Perhaps with these other users for superconducting magnets appearing, the development costs can be shared, rather than borne by high energy physics alone. The development of superconductivity for fusion and MHD will not be aimed at high energy physics type magnets, but the "spin off" benefits will undoubtedly profit us all. Oak Ridge National Laboratory has a multimillion dollar development program for magnets to be used in fusion machines. This program should lead to a better understanding of magnets in general and provide design information userul for high energy physics magnets.

\section{REFERENCES}

1. G. Morgan, et al., "Superconducting Magnet System for the AGS High Energy Unseparated Beam," 1975 Particle Accelerator Conforence, Session K (March 1975).

2. J. Purcell, et al., "Magnete for the ZCS Super conducting Stretcher Ring, " presented at the 1974 Applied Superconductivity Conference, Oakbrook, IIi. (Sept. 30-Oct. 2, 1974).

3. W. S. Gilbert, et al., "ESCAR Superconducting Magnet System, " 1975 Particle Accelerator Conference, Session D (March 1975).

4. W. B. Fowler, et al., "The Fermilab Energy Doubler, a Two-Year Progress Report, " 1975 Particle Accelerator Conference, Session D (March 1975).

5. P. Gavin, et al., "Operation of Superconducting Magnets in Fermilab Extracted Beams," 1975 Particle Accelerator Conference, contributed paper (March 1975). 